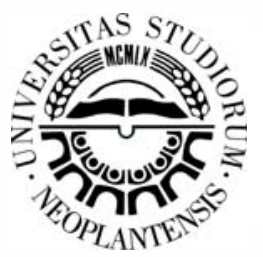

\title{
The effect of friction stirs welding speed on microstructure, mechanical properties and IGC of EN AW-5083 plates
}

\author{
Miloš Pavlovic ${ }^{a}{ }^{*}$, Ljubica Radovićc ${ }^{b}$ Igor Radisavljević ${ }^{b}$, Nenad Radovićc \\ ${ }^{a}$ Welding Institute, Gospodara Vučića 67, Belgrade, Serbia \\ ${ }^{b}$ Military Technical Institute, Ratka Resanovića 1, Belgrade, Serbia \\ ${ }^{c}$ Faculty of Technology and Metallurgy, Karnegijeva 4, Belgrade, Serbia
}

\begin{abstract}
The aim of this work was to evaluate the influence of welding speed on microstructure, mechanical properties, as well as Intergranular corrosion (IGC) susceptibility of EN AW-5083 alloy welded using FSW. FSW was performed using constant rotation speed of $750 \mathrm{rev} / \mathrm{min}$, while welding speed was varied from $73 \mathrm{~mm} / \mathrm{min}, 150 \mathrm{~mm} / \mathrm{min}$ to $190 \mathrm{~mm} / \mathrm{min}$. Results show that increase of welding speed lead to decrease of the size of the nugget. This behavior is attributed to decrease of heat input during welding. Accordingly, lower grain size provides increase of the strength. All tested welds are resistant to IGC, evaluating by mass loss according to NAMLT test, and resistivity slightly decrease with increasing welding speed.
\end{abstract}

Key words: friction stir welding, EN AW-5083 alloy, welding speed, heat input; microstructure, mechanical properties.

\section{INTRODUCTION}

Most important welding parameters in Friction Stir Welding are: welding force, tool rotational speed, welding speed, geometry of the tool and pin 1-4. Among these, tool rotational speed and welding speed affects the thermal cycle and the heat input [5-6]. Higher tool rotation speed generates higher friction heating and results in more severe stirring and mixing of material, while higher welding speed decreases the heat input 1 .

The heat input during FSW determines heating/ annealing in the nugget (stir zone), thermomechanical affected zone (TMAZ) and heat-affected zone (HAZ) and may result in recovery and/or recrystallization 7 . The microstructure changes are the most pronounced in the nugget. The grains are recrystallized, equiaxed and grain size is strongly dependant of chemical composition and FSW parameters [6, 8-10]. The size and distribution of the second phase particles, which have influence on the mechanical properties, are also changed during FSW processing [11-12].

The application of EN AW-5083 alloy demands testing the corrosion resistance of both base metal and welded joints. Al-Mg alloys with more than $3 \% \mathrm{Mg}$, due to the limited room temperature solubility of $\mathrm{Mg}$ in $\mathrm{Al}$ matrix
(1.9 wt. \% Mg), and precipitation of $\mathrm{Mg}$ rich particles $(\beta-$ $\mathrm{Al} 3 \mathrm{Mg} 2$ phase) on the grain boundary, are susceptible to IGC. $\beta-A 13 \mathrm{Mg} 2$ phase is determining factor for the resistance of the AA5xxx alloys to IGC 13-14.

During FSW welding severe plastic deformation and exposure to high temperatures causes a modification of microstructure and thus the microchemistry and the corrosion properties of the welded joints 15-16.

Nitric Acid Mass Loss Testing (NAMLT) [17], is the most common method for evaluating the susceptibility of Al-Mg alloys to IGC, since it provides a quantitative measure of susceptibility.

The aim of this work is to investigate the effect of welding speed on the mechanical properties and evaluate the intergranular corrosion resistance of FSW joint of EN AW-5083 plates.

\section{EXPERIMENTAL WORK}

\subsection{Material}

The material used in this study was commercial plate of EN AW-5083 (AlMg4.5Mn0.7) alloy, $6 \mathrm{~mm}$ thickness in as-received condition. 


\subsection{Welding}

The FSW parameters used in this study are given in Table 1. The welding direction was perpendicular to rolling direction. Tool with conical pin was used 18 .

Table 1-FSW parameters used in this work

\begin{tabular}{ccc}
\hline Specimen & $\begin{array}{c}\text { Rotation speed } \\
\text { (rev/min) }\end{array}$ & $\begin{array}{c}\text { Welding speed } \\
\text { (mm/min) }\end{array}$ \\
\hline A & 750 & 73 \\
B & 750 & 150 \\
C & 750 & 190 \\
\hline
\end{tabular}

\subsection{Microstructure}

The microstructures were characterized by a light microscope (LM). Metallographic samples were prepared using traditional grinding and polishing techniques using up to $3 / 5 \mu \mathrm{m}$ diamond paste. To reveal the grain structure, after electrolytic polishing in perchloric acid, the samples were etched in Barker's solution. All micrographs were taken on the $\mathrm{L}-\mathrm{S}$ plane

\subsection{Surface morphology after IGC test}

Surface morphology after IGC test was characterized by a stereo microscope and scanning electron microscope (SEM).

\subsection{Tensile test}

Uniaxial tensile tests were performed using transverse tensile specimens with $50 \mathrm{~mm}$ in gauge length and weld zone at the center. Test performed at room temperature, at strain rate of $\varepsilon=3.3 \cdot 10^{-3} \mathrm{~s}^{-1}$.

\subsection{Corrosion test}

The corrosion tests were carried out by means of susceptibility to intergranular corrosion (IGC). The susceptibility to IGC was determined by the nitric acid mass loss test (NAMLT) according to the ASTM G67 standard 17. Specimens, with dimensions $50 \times 6 \mathrm{~mm}$ and the thickness of the cold rolled plate of $6 \mathrm{~mm}$, were immersed in concentrated $\mathrm{HNO} 3$ at $30 \mathrm{C}$ for 24 hours, and the mass loss was measured. The $50 \mathrm{~mm}$ dimension of the specimens was parallel to the longitudinal direction of the plate (rolling direction). Three specimens were tested.

\section{RESULTS}

\subsection{Microstructure}

Fig. 1 shows the microstructures in welded joint. The micrograph of grain structure of the base metal (Fig. 1a) shows elongated grains along the rolling direction.
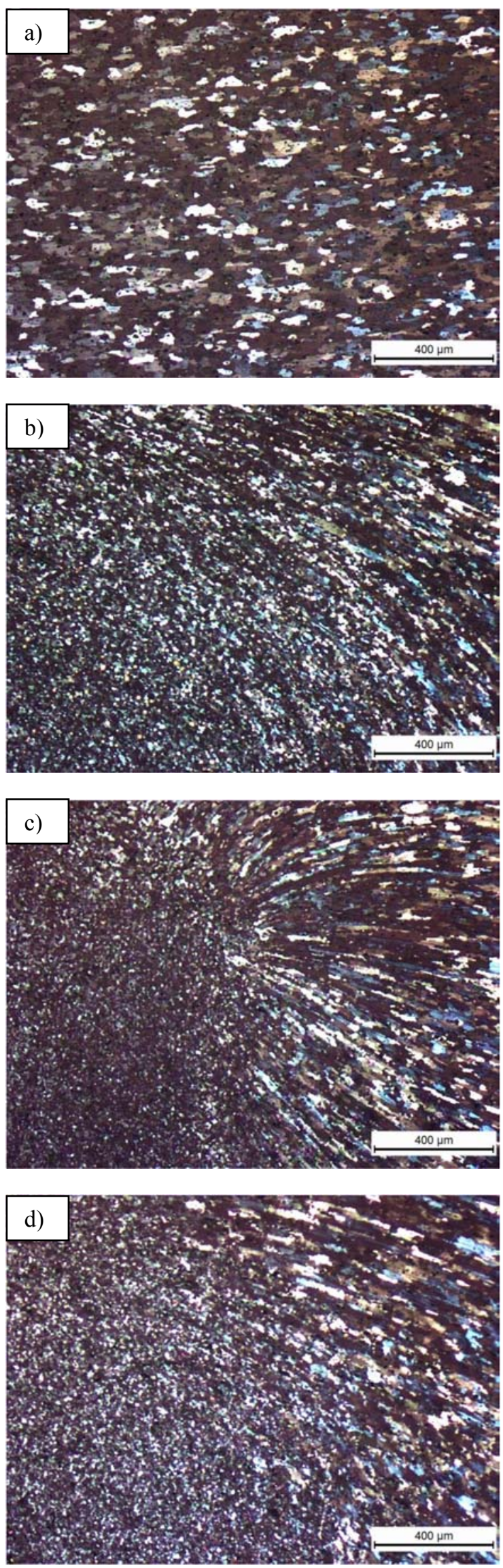

Fig. 1 Microstructure: a) base metal, b) specimen $A$; c) specimen $B$; d) specimen $\mathrm{C}$. 
The fine equiaxed recrystallized grains observed in the nugget and larger, highly deformed, elongated grains in advancing and retreating sides in TMAZ. The retreating side of the nugget and TMAZ of FSW specimens are shown in the (Figs. $1 \mathrm{~b}-\mathrm{d}$ ). The grain refinement is found to decrease from the nugget to HAZ.

\subsection{Mechanical properties}

Mechanical properties of the tested specimens are given in Table 2. Tensile strength of the FSW specimens is lower than the base metal and increased with increasing welding speed. Low elongations were measured after tensile tests.
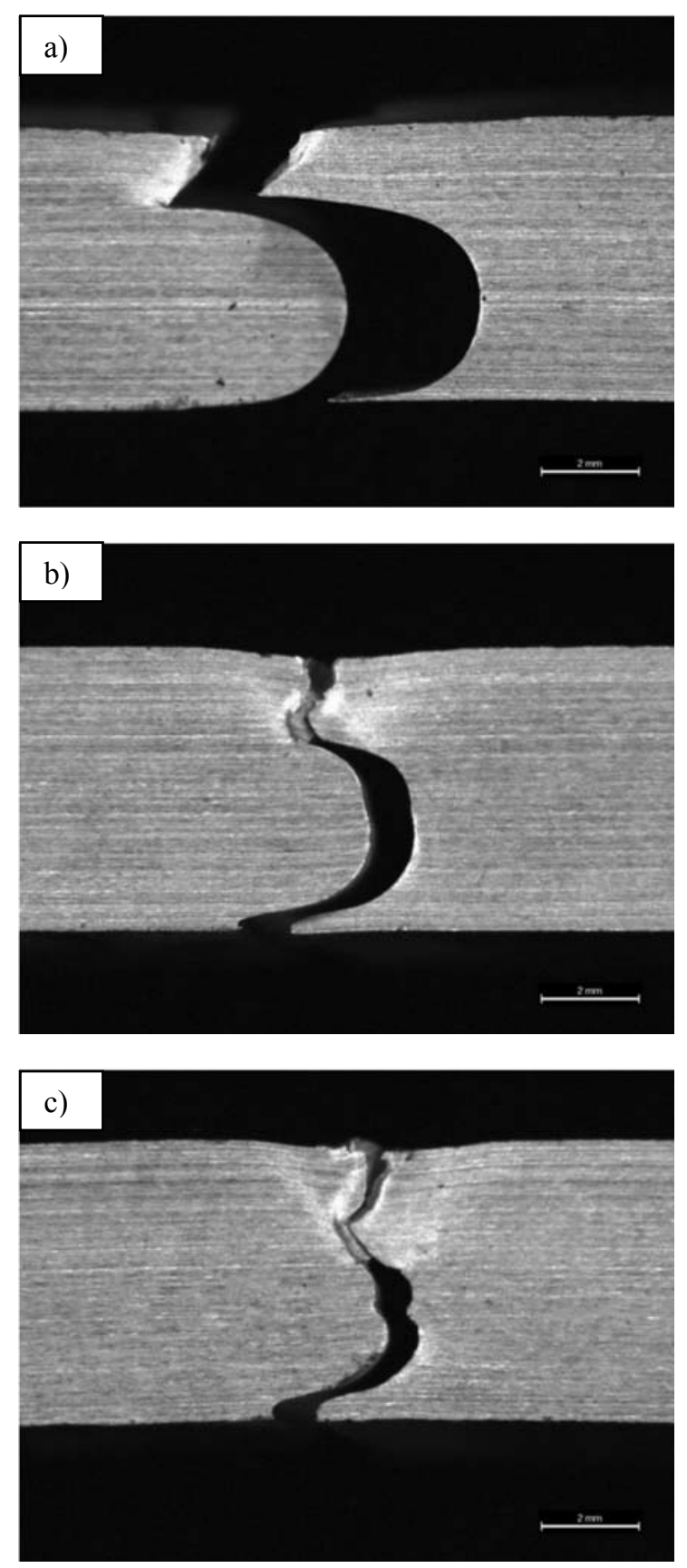

Fig 2 Specimens after tensile test: a) specimen $A$; b) specimen $B ; c$ ) specimen $\mathrm{C}$.
Table 2-Mechanical properties

\begin{tabular}{ccc}
\hline Specimen & $\boldsymbol{R m}(\boldsymbol{M P a})$ & $\boldsymbol{A}(\%)$ \\
\hline BM & 325 & 21.0 \\
$\mathrm{~A}$ & 171 & 1.43 \\
$\mathrm{~B}$ & 213 & 2.6 \\
$\mathrm{C}$ & 226 & 3.5 \\
\hline
\end{tabular}

The tensile specimens after tests are shown in Fig. 2. It was observed that all specimens fractured always along the nugget/TMAZ surface. This can explain low elongation during tensile tests.

\subsection{IGC susceptibility}

\subsubsection{Mass loss}

Table 3 shows the mass loss test (NAMLT) results. It can be seen that mass loss of all FSW specimens is, much less than base metal and less than $15 \mathrm{mg} / \mathrm{cm} 2$, which means that are not susceptible to IGC.

Table 3-Mass loss in NAMLT test

\begin{tabular}{cc}
\hline Specimen & Mass loss $(\mathbf{m g} / \mathbf{c m} 2)$ \\
\hline BM & 16,6274 \\
A & 4,0687 \\
B & 6,0786 \\
C & 6,2126 \\
\hline
\end{tabular}

\subsubsection{Surface morphology}

The morphology of the cross-section of the welded specimens after IGC test, observed visually and by stereo microscope, is shown in Figs. 3 and 4. Visually, surface morphology attack of the base metal specimens is uniform (Fig. 3a), while different color of the welding zones and the base metal and the end of the specimens, observed (Fig 3c-d). This implies the different corrosion attack of the FSW welds and base metal.

FSW specimens observed at higher magnification are shown in Fig. 4. Higher corrosion attack was observed at nugget/TMAZ interface and along typical "tail" shape toward face side, at all specimens. This test also revealed different shape and size of the nugget. At lower welding speed (specimen A), elliptical shaped nugget observed with an increase of the welding speed, the size of the nugget decreases, and near elliptical shape becomes more irregular.

SEM observation of the base metal specimens revealed localized intergranular attack on the rolling direction (Fig. 5a), while nugget, TMAZ and HAZ at all FSW specimens are covered by numerous different size pits. Also, between "onion layers" observed more intensive corrosion attack (Fig. 5b). 

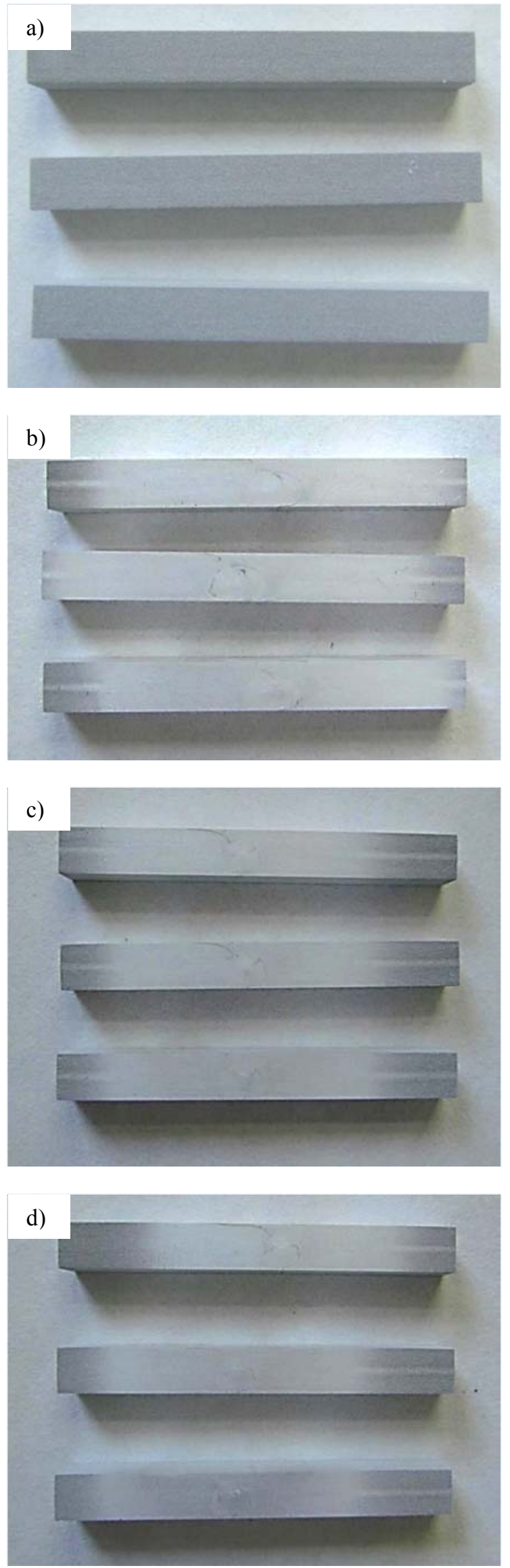

Fig. 3 Specimens of EN AW-5083 alloy after NAMLT test: a) base metal (AR); b) specimens $A$; $c$ ) specimens $B$ ); d) specimens $C$.
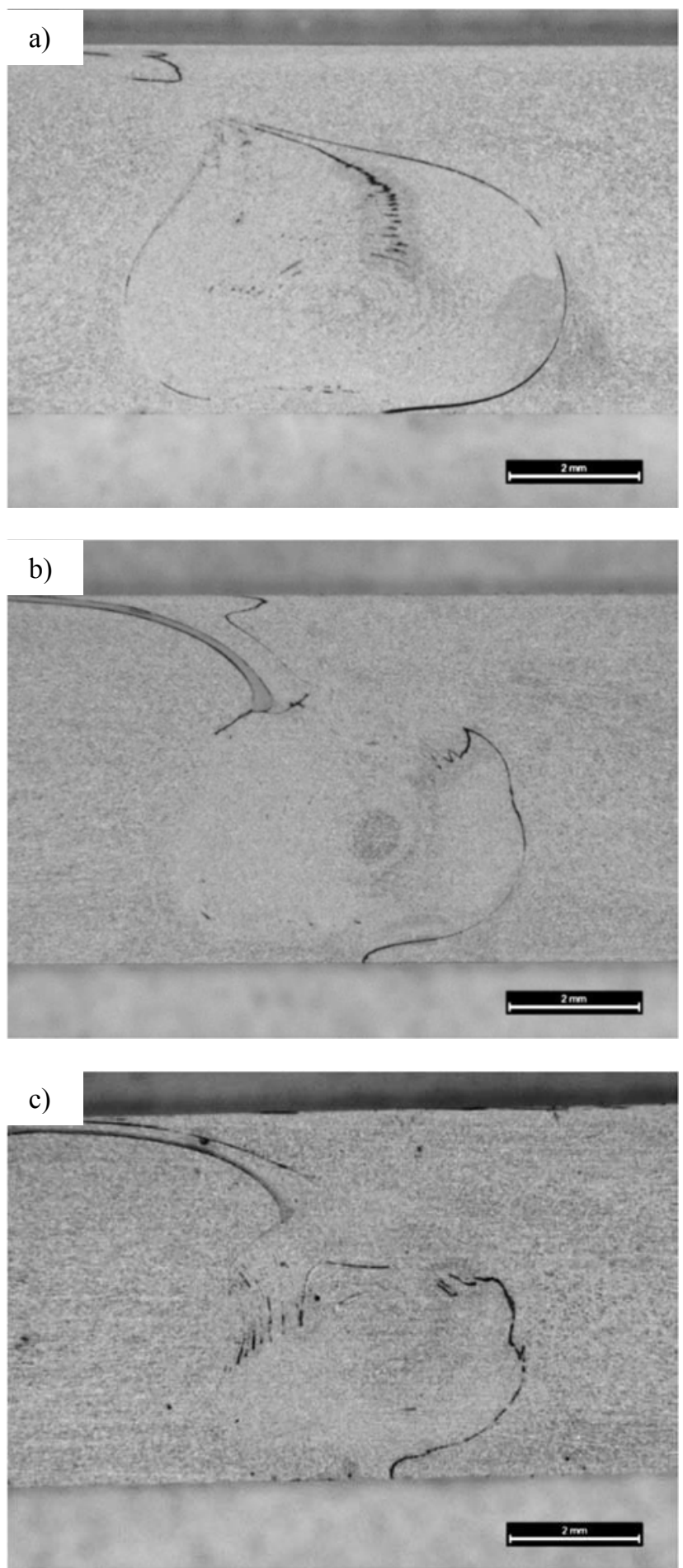

Fig. 4 Macrostructure of the welded specimens: a) specimen $A, b)$ specimen $B$ and c) specimen $C$. Stereo microscope.

\section{Discussion}

It is well known that macrostructure of the FSW specimens, i.e. weld nugget shapes and their size were strongly affected by the welding speed 19-20. Results in this work showed that with increases of the welding speed, the nugget shapes changed and nugget size decreases (Fig. 4). It is assumed that this can be caused by decrease of the heat input with increasing welding speed 1. Elliptical 
shape of the nuggets was formed due to high rotation speed. It is in accordance to previously research, which indicated that elliptical shaped nugget formed at rotation speed $700 \mathrm{rev} / \mathrm{min}$, while lower rotation speed, 300-500 $\mathrm{rev} / \mathrm{min}$, resulted in generation of basin-shaped nugget zone 19
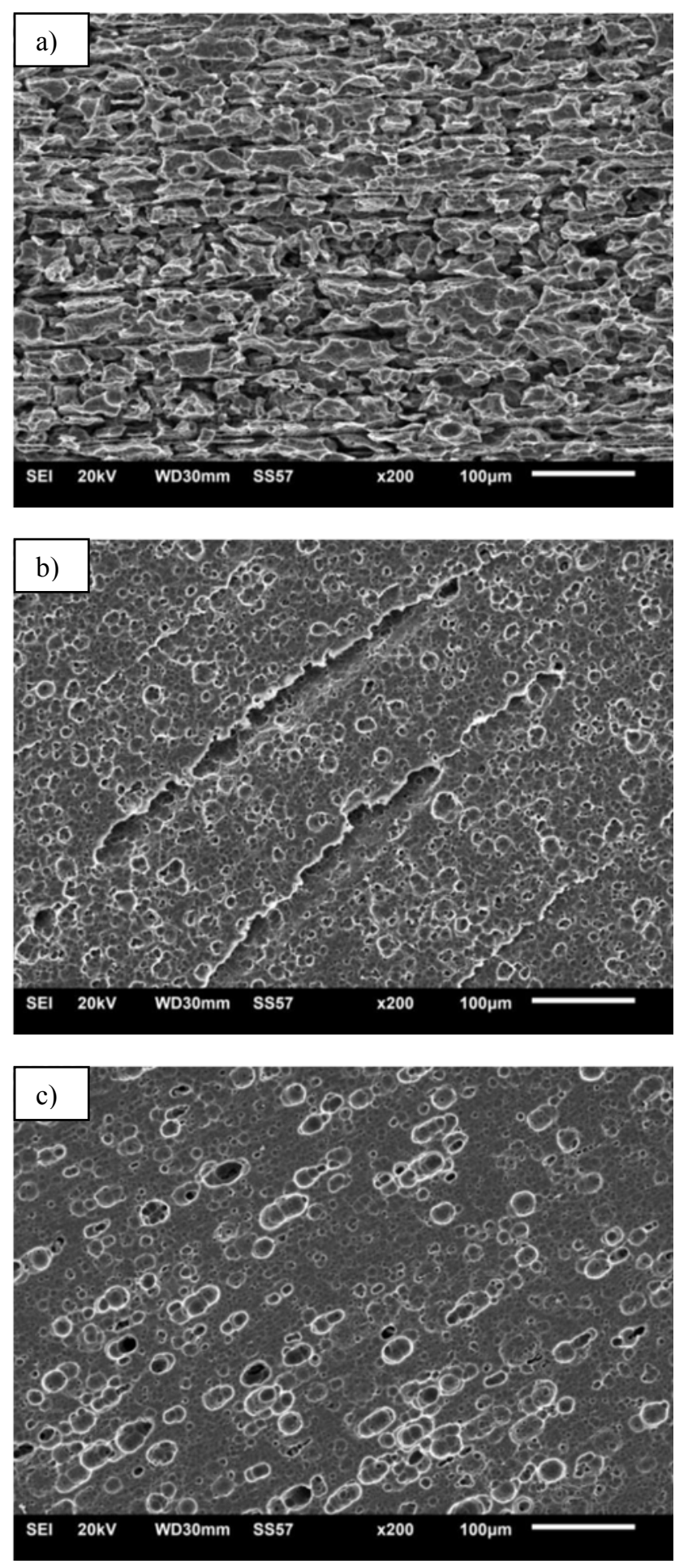

Fig. 5. SEM. Surface morphology after IGC test: a) base metal; b) FSW-nugget; c) FSW-TMAZ
Microscopic observation showed that the applied FSW parameters also have considerable effects on nugget structure (Fig. 1). Fine equiaxed grain structure formed in the nugget zones, due severe plastic deformation and dynamic recrystallization 21]. The grain size is affected by the welding parameters, but basically, it should depend on the heat input 1-3, 22.With increase of welding speed from $73 \mathrm{~mm} / \mathrm{min}$ to $150 \mathrm{~mm} / \mathrm{min}$ i.e. $190 \mathrm{~mm} / \mathrm{min}$, at constant rotation speed, heat input decreased and thus, it is expected that grain size decreased 2, 23. The lower grain size provides increase of the strength, what confirmed by tensile tests (Table 2). The welding speed influenced the mechanical properties of the welds. The tensile strength increased with increasing welding speed. The increase of the tensile strength with increasing welding speed can be influenced by both, decrease of the grain size of the nugget due to lower heat input, and decrease of the FSW welds (nugget) size in the specimens (Fig. 4), which has lower strength. Mechanical properties of the FSW specimens were significantly degraded by present defect, caused by low cohesion between nugget and TMAZ (Fig. 3), i.e. weak bond interface, so the tensile strength of the FSW specimens is lower than base metal. This feature should be subject to further research/investigation/examination.

According to results of NAMLT test, FSW specimens have less susceptibility to IGC compared to base metal. Since the test specimen consist of weld and base metal, and the total mass loss is sum of these masses, we can conclude that FSW welds of EN AW-5083 alloy have lower susceptibility to IGC compared to base metal. SEM analysis after corrosion tests showed different corrosion attack of the base metal and FSW welds after NAMLT test (Fig 5). While severe continuous attack at grain boundaries observed on the base metal (Fig. 5a), boundaries remains unchanged in both, nugget and TMAZ of FSW welds (Fig. 5 b, c), what explained the high resistance of the FSW to IGC. In the base metal, $\beta$ phase, which is determining factor for the resistance to IGC, was almost continuous precipitated at the grain boundaries. However, in FSW joints it seems that $\beta$ phase precipitated within the grains. This is attributed to microstructural changes during FSW. Severe plastic deformation (stirring) and recrystallization, provide modification the size and distribution of the second phase particles and precipitates, giving theirs more uniform distribution in grains than in the cold worked alloy 7, 19, as well as dissolution of the continuous precipitated anodic-phases, which are responsible for IGC resistance 24-25. These results are consistent with reported results by other authors 26-29, and for another Al-Mg alloy 16 It was also shown, that mass loss slightly increases with increasing welding speed. Considering the test specimens, the increase of mass loss can be attributed to decrease in the size of weld i.e. nugget and TMAZ zone (Fig. 4), as revealed by macroscopic inspection. 


\section{CONCLUSION}

The welding speed influenced the size and shape of nugget of the welds. The increase of the welding speed, at constant rotation speed, the nugget zone decreases, and its shape becomes irregular.

The results show that the increasing of welding speed (or decrease the heat input) at constant rotational speed increases the tensile strength.

Mechanical properties of the FSW joints were significantly degraded by present defect, caused by low cohesion between nugget and TMAZ, i.e. weak bond interface.

All tested FSW welds are resistant to IGC, evaluating by mass loss according to NAMLT test. These specimens showed better IGC resistance than base metal. It is attributed to microstructure refinement in welded zones compared to base metal.

IGC resistance slightly degraded with increasing welding speed. It is attributed to decrease of the size of the nugget, i.e. increase of the influence of the less IGC resistant base metal.

\section{ACKNOMLEGMENT}

The authors are indebted to the Ministry of Education, Science and Technological Development of the Republic of Serbia for financial support through Project TR-34018.

\section{REFERENCES}

[1] D. Yi, T. Onuma, S. Mironov, Y. S. Sato and H. Kokawa, Evaluation of heat input during friction stir welding of aluminium alloys, Science and Technology of Welding and Joining VOL 22 NO 1, pp. 41-47. 2017

[2] T. Hirata, T. Oguri, H. Hagino, T. Tanaka, S. W. Chung, Y. Takigawa, K. Higashi, Influence of friction stir welding parameters on grain size and formability in 5083 aluminium alloy, Materials Science and Engineering A 456, pp. 344-349, 2017.

[3] Y. S. Sato, T. Onuma, K. Ikeda and H. Kokawa, Experimental verification of heat $\mathrm{p}$ during friction stir welding of $\mathrm{Al}$ alloy 5083, Science and Technology of Welding and Joining, Vol. 21 No 4, pp. 325-330, 2016.

[4] R. Kumar, K. Singh, S. Pandey, Process forces and heat input as function of process parameters in AA5083 friction stir welds, Trans. Nonferrous Met. Soc. China 22, pp. 288-298, 2012.

[5] L. N. Tufaro, I. Manzoni, H. G. Svoboda, Effect of Heat Input on AA5052 Friction Stir Welds Characteristics, Procedia Materials Science 8, pp. $914-923,2015$.

[6] B. Abnar, M. Kazeminezhad, A. H. Kokabi, Effects of heat input in friction stir welding on microstructure and mechanical properties of AA3003-H18 plates, Trans. Nonferrous Met. Soc. China 25, pp. 2147-2155, 2015.
[7] S. K. Tiwari, Dinesh Kumar Shukla, R. Chandra, Friction Stir Welding of Aluminum Alloys: A Review, International Journal of Mechanical, Aerospace, Industrial and Mechatronics Engineering Vol:7, No:12, 2013.

[8] N. Kumar, R.S. Mishra, C.S. Huskamp, K. K. Sankaran, Microstructure and mechanical behaviour of friction stir processed ultrafine grained Al-Mg-Sc alloy, Mat. Sci Eng. A, 528 pp. 5883-5887, 2011.

[9] P. Cavaliere, G. Campanile, F. Panella, A. Squillace, Effect of welding parameters on mechanical and microstructural properties of AA6056 joints produced by friction stir welding, J Mat Proc Tech 180 pp. 263-270, 2006.

[10] K. Surekha, B.S. Murty, K. Prasad Rao, Microstructural characterization and corrosion behavior of multi pass friction stir processed AA2219 aluminum alloy, Surf Coat Tech, 202 pp. 4057-4068, 2008.

[11] K. T. Huang, T. S. Lui, L.H. Chen, Effect of the microstructural features on the tensile properties and vibration fracture resistance of friction stirred 5083 alloy, J Alloy Compd, 509, pp.

7466-7472, 2011.

[12] A. Sullivan, J.D. Robson, Microstructure properties of friction stir welded and post-weld heat-treated 7449 aluminum alloy thick plate, Mat Sci Enf A 478, pp. 351-360, 2008.

[13] C. Vargel., Corrosion of Aluminum, Elsevier, 2004.

[14] M. Kciuk, Structure, mechanical properties and corrosion resistance of AlMg5 alloy, J Achiev Mat Manuf. Eng., Vol. 17 ISSUE 1-2, 2006.

[15] R.A. Behnagh, M.K. Besharati Givi, M. Akbari, Mechanical Properties, Corrosion Resistance, and Microstructural Changes during Friction Stir Processing of 5083 Aluminum Rolled Plates, Materials and Manufacturing Processes, 27, 636640, 2012.

[16] Lj. Radović, I. Radisavljević, M. Bučko, Corrosion behavior of friction stir welded AlMgMn alloy, Zavarivanje i zavarene konstrukcije, 4/2017, pp. 161-167, 2017.

[17] Standard Test Method for Determining the Susceptibility to Intergranular Corrosion of 5XXX Series Aluminum Alloys by Mass Loss After Exposure to Nitric Acid (NAMLT Test).

[18] I. Radisavljevic, A. Živković, N.Radović, V. Grabulov, Influence of FSW parameters on formation quality and mechanical properties of $\mathrm{Al}$ 2024-T351 butt welded joints, Trans. Nonferrous Met. Soc. China 23, pp. 3525-3539, 2013.

[19] R.S. Mishra, Z.Y. Ma, Friction stir welding and processing, Materials Science and Engineering R, 50, pp. 1-78, 2005.

[20] B.Verlinden, J. Driver, I. Samajdar, R.D. Doherty Thermo-Mechanical Processing of Metallic Materials, Pergamon Materials Series, Ed by R. Kahn, 2007. 
[21] M.W. Mahoney, C.G. Rhodes, J.G. Flintoff, R.A. Spurling, W.H. Bingel, Properties of Friction-StirWelded 7075 T651 Aluminum, Met Mat Trans A, Volume 29a, 1998-1955.

[22] Z.Y. Ma, R.S. Mishra, M.W. Mahoney, Superplastic deformation behavior of friction stir processed $7075 \mathrm{Al}$ alloy, Acta Materialia $50 \mathrm{pp}$. 4419-4430, 2002.

[23] Hong-feng Wang, Jian-li Wang, Wei-wei Song, Dun-wen Zuo, Ding-lin Shao, Analysis on the Corrosion Performance of Friction Stir Welding Joint of 7022 Aluminum Alloy, Int. J. Electrochem. Sci., 11, pp. 6933 - 6942, 2016.

[24] J.L. Searles, P.I. Gouma, R.G. Buchheit, Stress Corrosion Cracking of Sensitized AA5083 (Al4.5Mg-1.0Mn), Vol. 32A, Met Mat Trans A, Vol. 32A, pp. 2859-867, 2001.

[25] J. R. F. Ramírez, The Role of Magnesium in the Electrochemical Behavior of 5XXX AluminumMagnesium Alloys, Pennsylvania State University, University Park, PA. (USA),
2006.

[26] R. Abdi Behnagh, M. K. Besharati Givi, and M. Akbari, Mechanical Properties, Corrosion Resistance, and Microstructural Changes during Friction Stir Processing of 5083 Aluminum Rolled Plates, Materials and Manufacturing Processes, 27: pp. 636-640, 2012.

[27] P. Vilaça, N. Pépe, L. Quintino, Metallurgical and corrosion features of friction stir welding of AA5083-H111, Welding in the World, Le Soudage Dans Le Monde 50(9-10), pp. 55-64, 2013.

[28] F. Zucchi, G. Trabanelli and V. Grassi, Pitting and stress corrosion cracking resistance of friction stir welded AA 5083, Materials and Corrosion 52, pp. 853-859, 2001.

[29] H. S. Grover, Vikas Chawla and Gurbhinder Singh Brar, Comparing Mechanical and Corrosion Behavior of TIG \& FSW Weldments of AA5083H321, Indian Journal of Science and Technology, Vol. 10(45), pp. 1-8, 2017. 